\title{
3 Research Square

\section{Transcriptomic Analyses of Differential Host Responses to Red Rot Pathogen Colletotrichum Falcatum in Sugarcane Through Subtractive Library and NGS Approach}

\section{Sathyabhama}

ICAR Sugarcane Breeding Institute

Rasappa Viswanathan ( $\square$ rasaviswanathan@yahoo.co.in )

ICAR Sugarcane Breeding Institute https://orcid.org/0000-0002-7274-8144

C.N. Prasanth

ICAR Sugarcane Breeding Institute

P. Malathi

ICAR Sugarcane Breeding Institute

\section{A. Ramesh Sundar}

ICAR Sugarcane Breeding Institute

\section{Research Article}

Keywords: Sugarcane, Colletotrichum falcatum, Differential host response, SSH, Illumina high throughput sequencing, qRT-PCR, PAMP, PTI, ETI, Defense, Signalling

Posted Date: December 1st, 2021

DOI: https://doi.org/10.21203/rs.3.rs-1112420/v1

License: (c) (i) This work is licensed under a Creative Commons Attribution 4.0 International License.

Read Full License 


\section{Abstract}

The fungal pathogen Colletotrichum falcatum causes the stalks, the economically important for sugar extraction. Although, disease management is achieved by cultivating resistant cultivars, the complex polyploidy of sugarcane genome complicates understanding the inheritance of disease resistance. Earlier attempts of using resistant and susceptible varieties to understand host-pathogen interaction resulted in cultivar specific expression of genes due to different genomic background of the varieties. To avoid host background variation in the interaction, suppression subtractive hybridization (SSH) based next generation sequencing technology was utilized in the same cv Co 7805 which behaves differently as incompatible and compatible to two different $C$. falcatum pathotypes. In the incompatible interaction (ICI) with $C$. falcatum pathotype $C$ f 87012 (Less virulent, LVir) 10,038 contigs were assembled from $\sim 54,699,263$ raw reads. In the compatible interaction $(\mathrm{Cl})$ to the $C$. falcatum pathotype $C f 94012$ (Virulent, Vir) 4022 contigs were assembled from $\sim 52,509,239$ raw reads. The transcripts homologous to CEBiP receptor and transcripts involved in the signals $\mathrm{ROS}, \mathrm{Ca}^{2+}, \mathrm{BR}, \mathrm{JA}$ and $\mathrm{ABA}$ were exhibited in both the responses. Additionally, MAPK, ET, PI signals and JA amino conjugation related transcripts were found only in ICl. Finally, the temporal gene expression of a total number of 16 transcripts was monitored in qRT-PCR. Most of the transcripts exhibited highest induction in $\mathrm{ICl}$ in comparison with $\mathrm{Cl}$. Further, more than 17 transcripts specific to the pathogen were found only in $\mathrm{Cl}$, indicating that the pathogen colonizes the host tissue whereas it failed to to do so in ICl. Overall, this study has identified for the first time, the differential responses of a single sugarcane host to two different $C$. falcatum pathotypes and PAMP triggered immunity (PTI) is exhibited in both the responses, but the more efficient effector triggered immunity (ETI) was found only in $\mathrm{ICl}$ at the molecular level.

\section{Introduction}

Plants, being sessile are continuously exposed to various biotic and abiotic stresses during their lifetime. Among them, biotic stresses caused by the invading pathogen often results in complete devastation of the diseased plant. To cope up with the pathogen stress, plants have evolved sophisticated defense strategies to recognize and restrict pathogen invasion by activating their immune responses. At the plantpathogen interface, plant perceives pathogenicity determinants termed pathogen associated molecular patterns (PAMPs) such as chitin and glucans present in the pathogen cell wall by the cognate pattern recognition receptors (PRRs) located at the surface of plasma membrane and triggers defense responses termed PAMP triggered immunity (PTI). Successful pathogens evade this host detection by secreting effector proteins and make the host susceptible to pathogen invasion known as effector triggered susceptibility (ETS). Whereas, the effector proteins of pathogens are recognized by a set of resistance (R) genes present in the plant which further activate host defense termed as effector triggered immunity (ETI). This mode of defense is stronger and often termed as R-gene mediated defense or gene for gene interaction. PTI emerges as a basal defense to prevent further colonization of the pathogen. ETI leads to hypersensitive response mediated programmed cell death (HR-PCD) and enhanced resistance at the whole plant level which is long lasting (Hamdoun et al. 2013). Resistance is determined by a set of $R$ 
genes localized at the surface of the plant plasma membrane or the cytoplasm. Flor's gene for gene hypothesis states that a specific $\mathrm{R}$ gene in the plant recognizes its cognate avirulence (Avr) gene in the pathogen. Specific recognition results in provoking defense gene expression in the plant system (Ali \& Reddy, 2000; Beers \& McDowell, 2001). During evolution, new resistant specificities are generated to cope with the newly evolved virulent strains of pathogens. Some R genes such as Hm1 and RPM1 are present as single copy in resistant plants and are absent in the susceptible plants (Flor, 1971). But most of the $R$ genes are organized in complex loci containing an array of homologous genes. For example, Rp1, Rpp5, Xa21, Pto, Dm3, I2, N, M and Cf genes are localized in a cluster (Gao et al. 2000; Grant et al. 1995). In a crop with complex polyploidy and aneuploidy, the R genes must be organized in a complex locus. The polyploid nature and genetic complexity of sugarcane, makes it difficult to find a specific $\mathrm{R}$ gene for a particular disease/pathogen. So far, Bru1 is the only known resistant gene conferring resistance to brown rust and is found to segregate in a Mendelian pattern of 3:1 (Asnaghi et al. 2004).

Sugarcane (Saccharum spp. hybrid) is an economically important crop cultivated in tropical and subtropical regions of the world. India ranks second in sugarcane production next to Brazil (www.fao.org/corp/statistics/en/). Red rot caused by the ascomycete fungal pathogen Colletotrichum falcatum Went (Teleomorph: Glomerella tucumanensis [Speg.] Arx and Muller) is a serious threat for sugarcane cultivation in the tropical regions of the world (Viswanathan 2010, 2021a). Management of the disease depends solely on cultivating red rot resistant cultivars. However, during the past decades, severe disease epidemics have occurred that resulted in removal of many elite cultivars from cultivation. Frequent emergence of new variants of the pathogen $C$. falcatum contributes to the varietal breakdown (Viswanathan and Rao 2011). Hence, detailed studies were conducted on the molecular basis of the interaction between sugarcane and $C$. falcatum to understand the host resistance mechanism by our research group. Firstly, early and prominent induction of pathogenesis-related (PR) proteins was documented as a defense and induced defense response against $C$. falcatum (Viswanathan et al. 2003, 2005). In addition to induction of the PR proteins, accumulation of phytoalexins at the pathogen infection site was documented as marker for red rot resistance (Malathi et al. 2008, Kumar et al. 2015, Nandakumar et al. 2021a). The chitinase gene from sugarcane has been characterized as a class IV glycosyl hydrolase based on full gene sequence and in silico 3D structure prediction. Further, the differential expression of the chitinase gene in red rot resistant and susceptible sugarcane cultivars was monitored through qRT-PCR (Rahul et al. 2015). Differential display (DD)-RT-PCR was used to identify differential transcripts upregulated during pathogenesis of $C$. falcatum in resistant and susceptible cultivars of sugarcane (Pratima et al. 2013, Rahul et al. 2016).

The NGS based sequencing technology plays a vital role in exploring genes and genomes of an organism. The whole genome and transcriptome of $C$. falcatum were sequenced using Illumina Hi-Seq 2500 (Viswanathan et al. 2016, Prasanth et al. 2017). Earlier we adopted suppression subtractive hybridization (SSH) strategy to identify the time specific and initial defense responses of sugarcane during $C$. falcatum pathogenesis which hypothesized involvement of jasmonic acid (JA), ethylene (ET), reactive oxygen species (ROS), phosphoinositide $(\mathrm{PI})$ and calcium $\left(\mathrm{Ca}^{2+}\right)$ signals in disease 
resistance(Sathyabhama et al. 2015, 2016). The previous transcriptomic studies, a set of sugarcane cultivars varying in red rot resistance, either a resistant or a susceptible host were used to determine differential transcripts upregulated during $C$. falcatum pathogenesis (Pratima et al. 2013, Sathyabhama et al. 2015, 2016). The variation in transcript accumulation between resistant and susceptible varieties we cannot rule out the changes in transcriptomes due to their genetic complexity and this may have a profound influence on identifying the genes/proteins involved in pathogen defense in sugarcane. In our experimental trials, certain cultivars of sugarcane, exhibiting differential host responses to different pathotypes of $C$. falcatum was established (Viswanathan et al. 2020). In this study, the sugarcane cv Co 7805 exhibiting incompatible (ICl) and compatible (Cl) interactions to Cf87012 and Cf94012, respectively was used for SSH and subtracted transcriptome sequencing and to identify the initial defense responses exhibited in sugarcane against $C$. falcatum in fool-proof manner. Illumina HiSeq 2000 sequencing platform was used to sequence subtracted transcripts derived from the two responses. This study generated comparative transcriptomes of $\mathrm{ICl}$ and $\mathrm{Cl}$ in sugarcane against $C$. falcatum and identified detailed information on resistance mechanism in sugarcane to $C$. falcatum for the first time.

\section{Materials And Methods}

\section{Plant material and pathogen culture}

A tropical sugarcane cv Co 7805 was planted in sugarcane field at ICAR-Sugarcane Breeding Institute (SBI) (ICAR), Coimbatore, India and the crop was raised following standard field practices for a tropical sugarcane. Two pathotypes of $C$. falcatum isolated from infected stalk tissue samples of sugarcane cv Co 87012 and Co 94012 named as pathotypes Cf87012 and Cf94012 respectively, maintained as part of C. falcatum culture collections, Plant Pathology lab, ICAR-SBI, Coimbatore were used for this study. The differential response of sugarcane cv Co 7805 to the two pathotypes Cf87012 and Cf94012 was assessed over a period of three years. The cultivar consistently showed incompatible response upon inoculation with the pathotype $C f 87012$ and compatible response to the pathotype $C f 94012$ (Fig. 1). Pathogen inoculation was performed by plug method in the third internode from the base of the cane following standard protocol for sugarcane cultivar as reported earlier (Mohanraj et al. 2012, Viswanathan et al. 2021). Separate sets of sugarcane stalks of the cv Co 7805 were inoculated in triplicates with the two $C$. falcatum pathotypes and mock inoculated samples served as controls for the experimental samples. Stalk tissue samples were collected in triplicates with their respective controls $36 \mathrm{~h}$ post $C$. falcatum inoculation and stored in $-80^{\circ} \mathrm{C}$ till RNA isolation.

\section{RNA extraction and suppression subtractive hybridization (SSH)}

Total RNA was extracted from all the samples with TRI reagent (Sigma-Aldrich, USA). The quality of RNA was checked in an agarose gel and quantified in a NanoDrop ${ }^{\mathrm{TM}} 1000$ spectrophotometer (Thermo Scientific, USA). $1 \mu \mathrm{g}$ of purified RNA was used for CDNA synthesis following the manufacturer's 
instructions of Smarter ${ }^{\mathrm{TM}}$ PCR cDNA synthesis kit (Clontech, CA, USA). Forward and reverse subtractions for the cDNAs were done following the manufacturer's instructions of PCR-Select ${ }^{\mathrm{TM}}$ cDNA subtraction kit (Clontech, CA, USA). Forward subtraction represents resistance response library (RRL), in which cv Co 7805 challenged with pathotype Cf87012 was used as tester, cv Co 7805 challenged with $C f 94012$ and mock sample of cv Co 7805 were used as the driver. In reverse subtraction representing susceptible response library (SRL), the cv Co 7805 challenged with Cf94012 was used as tester and cv Co 7805 challenged with the pathotype Cf87012 and mock sample of cv Co 7805 were used as driver.

\section{Illumina library construction and sequencing}

The cDNA pools of the subtracted two transcripts were sequenced by Illumina HiSeq 2000 paired end (PE) sequencing platform at Xcelris Genomics Pvt Ltd, Ahmadabad, Gujarat India. The two subtracted ds cDNAs were fragmented using Covaris S2 (Covers Inc., Massachusetts, USA). After fragmentation, Illumina indexing adapters were added to the blunt ends and size selected in the range of 300-600 bp in $2 \%$ agarose-Etbr gels. The two subtracted ds cDNAs were prepared for sequencing according to the Illumina TruSeq DNA sample preparation guide v2 (August 2011, rev. A) (Illumina Inc, San Diego, USA) for Illumina Paired-End (PE) Multiplexed sequencing. Cluster generation was carried out for the PE library by hybridization of template DNA molecules onto the oligonucleotide-coated surface of flow cell v3 (Illumina Inc., San Diego, USA). Immobilized DNA template copies were amplified by bridge amplification to generate clonal DNA clusters. The process of cluster generation was performed on $C B O T$ using TruSeq PE Cluster kit v3-cBot-HS (Illumina Inc., San Diego, USA). TruSeq SBS v3-HS kits (Illumina Inc., San Diego, USA) were used to sequence DNA of each cluster on a flow cell using sequencing by synthesis technology on the Illumina HiSeq 2000 flow cell v3. Samples were sequenced using 100bp PE runs.

\section{Transcript assembly and annotation}

The raw reads were quality trimmed; adaptor sequences removed and the reads were size selected using Trimmomatic v0.17. After adaptor trimming, high quality reads with mean quality scores more than 25 and sequence length longer than $50 \mathrm{bp}$ were selected for assembly. De novo assembly of the subtracted transcript assembled contings were performed in a CLC genomics workbench v6.0. Functional annotation of the assembled transcript contigs were predicted with gene ontology (GO) terms through BLASTx analysis using BLAST2GO program. An e-value threshold of $\mathrm{e}^{-5}$ and a high scoring segment pair (hsp) filter of 33 were kept as default parameters for similarity search. Sequences less than 100 were filtered and removed.

\section{Pathway analysis by KEGG-KAAS}

The transcript assembled contigs that belong to the metabolic pathways that are expressed in the interaction were identified through mapping the assembled transcripts to Kyoto Encyclopedia for Genes and Genomes (KEGG) eukaryotic database using KEGG Automatic Annotation Server (KAAS). All the transcripts were compared against KEGG-KAAS database using BLASTx with default threshold bit-score value of 60 . 


\section{Validation of gene expression through qRT-PCR}

Temporal gene expression of 16 transcripts mapped to KEGG-KAAS database was studied in (Step One Plus ${ }^{T M}$ Real-Time PCR Systems, Applied Biosystems Inc., Life Technologies, USA). Representative transcripts involved in recognition, signalling and defense were studied. The transcripts include chitin elicitor binding protein (CEBiP), mitogen activated protein kinase kinase kinase 1 (MAPKKK1), mitogen activated protein kinase kinase 1 (MAPKK1), Brassinosteroid signalling kinase (BRSK), disease resistant protein RPM1 (DRPRPM1), disease resistant protein RPS5 (DRPRPS5), cyclic nucleotide gated channel (CNGC), calcium dependent protein kinase (CDPK), calcium binding protein CML (CBPCML), superoxide dismutase Cu Zn (SOD Cu Zn), V type proton transporting ATPase subunit1 (VTPATPase), jasmonic acid aminoacid synthetase (JAAS), Abscisic acid responsive element binding factor (ABAREBF), ethylene receptor (ER), 14-3-3 protein epsilon (14-3-3 PE) and Chitinase. The sugarcane cv Co 7805 stalks inoculated with $C$. falcatum pathotypes $C f 87012$ and $C f 94012$ were collected at 12,36 and $72 \mathrm{~h}$ post $C$. falcatum inoculation. Total RNA was extracted by TRI reagent (Sigma-Aldrich, USA). $500 \mu \mathrm{g}$ of total RNA was used for CDNA synthesis; first strand CDNA was diluted further to 200ng and used as templates for qRT-PCR. SYBR green PCR mastermix (Applied Biosystems Inc., Life Technologies, USA) was used for the analysis. 25SrRNA was used as the internal control. The list of primers is represented in Table 1.

\section{Results}

\section{Transcriptome sequencing and denovo assembly}

The number of raw reads generated by Illumina HiSeq 2000 was 54,699,263 and 52,509,239 for RRL and SRL with respective the number of filtered reads was $41,025,151$ and $42,001,812$. Quality trimming, adaptor sequence removal and size selection of transcript reads resulted in a total of 10,038 and 4,022 high quality reads for RRL and SRL, respectively. Analyses of two sets of transcripts assigned the transcripts to the 7,849 and 2,899 transcripts for RRL and SRL through BLASTx. There was no homology for 2,189 and 1,123 for RRL and SRL, respectively and they are described as novel genes or hypothetical proteins. The transcripts were submitted in NCBI sequence read archive (SRA) database, with accession numbers SRR2992210 and SRR 2992249 for RRL and SRL respectively.

\section{BLAST homology with other species and annotation}

In RRL, the BLAST hits constituted to maximum homology of 34\% with Sorghum bicolor followed by $32 \%$ with Zea mays and $4 \%$ with Oryza sativa. In case of SRL, the respective homologies were $42 \%, 27 \%$ and $5 \%$ for Sorghum bicolor, Zea mays and Oryza sativa. In RRL, 1\% homology in Triticum urartu, Vitis vinifera, Glycine Max, Hordeum vulgare and Medicago truncatula species were found. In SRL, no homology was found with those species. Saccharum officinarum and Populus trichocarpa had $1 \%$ homology in SRL, and no homology was found in RRL. Both RRL and SRL had $1 \%$ homology with Saccharum hybrid cultivar (Suppl. Fig. 1a, 1b). In both RRL and SRL, many of the transcripts from BLAST 
annotation were found to be hypothetical proteins or novel genes. So, to know the functional ontology of the differential transcripts, GO distribution and KEGG-KAAS functional categorization were done.

\section{Gene Ontology (GO) distribution}

The high-quality assembled transcripts were annotated with gene ontology (GO) terms. The GO terms were distributed as biological processes, molecular functions and cellular components (Fig. 2). In biological process, transcripts pertaining to aromatic amino acid family biosynthetic process, protein $\mathrm{N}$ linked glycosylation, small GTPase mediated signal transduction, GPI anchor biosynthetic process, IMP biosynthetic process and so on were expressed differentially in RRL. In SRL, transcripts pertaining to sucrose biosynthetic process, negative regulation of peptidase activity and protein deubiquitination were present. In cellular component, transcripts pertaining to RNA polymerase complex, cis-golgi network, anaphase-promoting complex, transcription factor TFIID complex, photosystem I \& II were present in RRL. In SRL, a single differential transcript pertaining to cullin-RING ubiquitin ligase complex was present. In molecular function, transcripts pertaining to shikimate kinase activity, cellulose synthase (UDP-forming) activity, P-P-bond-hydrolysis-driven protein transmembrane transporter activity, aspartic-type endopeptidase activity, serine-type endopeptidase activity and mannose-1-phosphate guanylyl transferase (GDP) activity were present in RRL. In SRL, serine-type endopeptidase inhibitor activity and quinone binding - oxidoreductase activity, acting on NADH or NADPH were present. The gene ontology of the $3 \mathrm{GO}$ terms is presented in Table 2.

\section{KEGG-KAAS functional annotation of subtracted transcriptome}

High quality reads corresponding to 10,038 for RRL and 4022 for SRL were mapped in KEGG-KAAS database. The transcripts were mapped to 12 categories pertaining to carbohydrate metabolism, energy metabolism, lipid metabolism, nucleotide metabolism, amino acid metabolism, glycan metabolism and biosynthesis, metabolism of cofactors and vitamins, metabolism of terpenoids and polyketides, biosynthesis of other secondary metabolites, genetic information processing, environment information processing and plant pathogen interaction. Of the total transcripts mapped, $42 \%$ were found to be present in both the interactions or unchanged during $C$. falcatum pathogenesis, $47 \%$ of the transcripts were upregulated in RRL and $11 \%$ of the transcripts were found to be upregulated in SRL. In all the categories several transcripts were mapped in common i.e., those transcripts were present in both the responses or unchanged during the interaction (Fig 3). The representative transcripts are listed in Table 3.

\section{Differential transcripts from Glomerella graminicola from BLAST homology search}

From the BLAST homology search, a total number of 17 transcripts homologous to Glomerella graminicola were present only in SRL. The transcripts represented pathogenic determinants of $G$. tucumanensis, the perfect stage of $C$. falcatum. The transcripts were found to be involved in fungal morphogenesis (alanine glyoxylate aminotransferase), intra cellular signal transduction (Ras), translation (ribosomal proteins), glycolysis (hexokinase), RNA splicing and the E3 Ub liagase of the Ub-26S proteasome pathway (Table 4). The expression of transcripts corresponding to the pathogen even after 
subtraction of cDNA suggested that the $C$. falcatum could colonize the host tissues in compatible interaction whereas transcripts related to $C$. falcatum colonization was not found in the incompatible interaction.

\section{Validation of gene expression through qRT-PCR}

The gene expression of the following transcripts CEBiP, MAPKKK1, MAPKK1, DRPRPM1, DRPRPS5, CBPCML, JAAS and ABAREBF showed a gradual increase in their expression at $12 \mathrm{~h}$ and $36 \mathrm{~h}$ and a decline at $72 \mathrm{~h}$ post $C$. falcatum inoculation in RR. Whereas, in SR, CEBiP, MAPKKK1 and CBPCML exhibited an inconsistency in their expression at all the time intervals. MAPKK1 and JAAS showed gradual decrease from $12 \mathrm{~h}$ to $72 \mathrm{~h}$. DRPRPM1 showed a similar response as RR but the transcript level was less than 2-fold. ABAREBF showed gradual raise from 12 to $72 \mathrm{~h}$ and reached 2.5 -fold at $72 \mathrm{~h}$ in SR which is higher than the RR. The defense gene chitinase showed a gradual raise in both RR and SR from 12 to $72 \mathrm{~h}$. However, the transcript accumulation was found to be higher in RR and reached a maximum of 4 -fold at $72 \mathrm{~h}$ post $C$. falcatum inoculation. The transcripts CNGC and CDPK showed a gradual increase in $\mathrm{RR}$ and a gradual decrease in SR from 12 to $72 \mathrm{~h}$ post $C$. falcatum inoculation. The transcripts 14-3-3 PE and SOD Cu Zn showed an increase in expression from 12 to $36 \mathrm{~h}$ and a decline at $72 \mathrm{~h}$ in the SR. In RR, there was an unstable expression. 5-fold expression was noticed in RRL for SOD Cu-Zn at $12 \mathrm{~h}$ post $C$. falcatum inoculation. For, VTP ATPase, the expression in RR was unstable and SR showed a constant 6fold expression at 36 and $72 \mathrm{~h}$ post $C$. falcatum inoculation. BRSK and ER showed an inconsistent expression in both the responses. At 12h, BRSK showed more than 5-fold expression in RR. At 36h ER showed more than 10-fold expression in SR. Overall, incompatible interaction revealed higher expression of different transcripts associated with host resistance to defense upon $C$. falcatum inoculation whereas in the compatible interaction, except for a few transcripts where the gene expression was not prominent.

\section{Discussion}

Red rot, caused by the fungal pathogen Colletotrichum falcatum is a devastating disease of sugarcane crop. The survival of a sugarcane cultivar in India is highly linked to red rot resistance in almost all parts of sugarcane cultivating regions of the country. Once, the popular cultivars are affected by red rot, they cannot be propagated in the field and has to be removed from cultivation. The pathogen infection causes complete devastation of the crop under field conditions. Hence, concerted efforts were given to identify red rot resistant cultivars in sugarcane varietal development programmes (Viswanathan, 2021b). During the last two decades, considerable efforts were made to understand defense strategies adopted by sugarcane in response to $C$. falcatum. Evidences of induction of PR-proteins and 3-deoxyanthocyanidin phytoalexins as biochemical defense responses during $C$. falcatum pathogenesis were found (Viswanathan et al. 2005; Malathi et al. 2008; Kumar et al. 2015). In recent years, through massively parallel next generation sequencing (NGS), a large number of transcripts at the interface of plant pathogen interaction has been sequenced and identified many candidate genes responsible for resistance or susceptibility. In this study, forward and reverse subtracted transcriptomes captured during sugarcane - C. falcatum interaction were sequenced through an NGS-Illumina Hi-Seq 2000 sequencing 
platform. The pathotype Cf87012 (LVir) exhibited incompatible interaction (ICI) and the pathotype Cf94012 (Vir) exhibited compatible interaction (Cl) when inoculated on the sugarcane cv Co 7805 which exhibited a differential host interactions. A total of 10,038 and 4,022 transcripts were derived for ICl and $\mathrm{Cl}$ respectively. In that, only 7,849 and 2,899 transcripts had BLAST homology for $\mathrm{ICl}$ and $\mathrm{Cl}$, respectively. The transcripts were mapped in KEGG-KAAS for functional categorization and biochemical pathway analysis (Fig. 3). Finally, a hypothetical model representing the probable occurrence of PTI in both ICI and $\mathrm{Cl}, \mathrm{ETI}$ in $\mathrm{ICl}$ and ETS in $\mathrm{Cl}$ has been proposed in sugarcane for the first time.

In this study, a transcript homologous to chitin elicitor binding protein (CEBiP), and a S/T protein kinase were induced in both $\mathrm{ICl}$ and $\mathrm{Cl}$. In rice, the chitin molecule/elicitor of the fungal pathogen, Magnaporthe grisea is perceived by an extracellular LysM receptor containing chitin elicitor binding protein (CEBiP), a PRR (Kaku et al. 2006). PRRs recognize both pathogen-derived nonself PAMPs/MAMPs and plant-derived DAMPs, which triggers PTI. But the transcripts involved in downstream signalling namely MAPK and PI were present only in $\mathrm{ICl}$. Even though, there is probable occurrence of $\mathrm{PTI}$ in both $\mathrm{ICl}$ and $\mathrm{Cl}$, the magnitude of signals activated by MAPK, JA and PI may be higher in ICI which is probably responsible for resistance than the $\mathrm{Cl}$ (Fig. 4). The pathogen responsive MAPK activation is likely to promote the generation of ROS in chloroplasts and JA signalling, which plays an important role in execution of HR cell death in plants. Usually, the virulent pathogen secretes effectors to make the plant susceptible or to evade PTI termed ETS (Jones et al. 2006). In this study, from BLAST homology search, it is evident that, unlike the pathotype Cf87012, Cf94012 penetrated the host surface. The pathogenic transcripts homologous to G. graminicola involved in primary metabolites production and the transcript; alanine-glyoxylate amino transferase involved in fungal morphogenesis were upregulated only in $\mathrm{Cl}$ (Table 4). The transcripts captured in $\mathrm{Cl}$ homologous to $\mathrm{G}$. graminicola must be indicating successful pathogenesis and the pathogen's proliferating stage inside the susceptible host. Also, recent studies by Bhadauria et al (2012 a, b) have demonstrated the essential role of the enzyme alanine: glyoxylate aminotransferase (AGT1) in the rice blast pathogen Magnaporthe oryzae. AGT may provide a means to maintain redox homeostasis in appressoria and contribute to the triglyceride mobilization from conidia to appressoria. Similarly, in the interaction between sugarcane and $C$. falcatum, the role of AGT must be essential to transfer nutrients and enhance lipid mobilization which is very much needed for melanisation of appressorium utilizing the glycerol during pathogenesis.

In the present study, only in ICl, the transcripts homologous to disease resistance proteins RPM1, RPS2 and RPS5 were upregulated. qRT-PCR experiments carried out in $\mathrm{ICl}$ and $\mathrm{Cl}$, at three-time intervals post pathogen inoculation revealed the transcriptional gene expression of RPM1 and RPS 5 in both the responses $(\mathrm{ICl}$ and $\mathrm{Cl}$ ). But the magnitude of expression was higher in $\mathrm{ICl}$ (Fig. 4). Also, RPS5 was found to be more than 40 -fold in $\mathrm{ICl}$, but a constant expression of 5 -fold was noticed in $\mathrm{Cl}$ throughout the period of study (Fig. 4). Probably, here, proteins involved in the decoy model of defense may exist and the pathogenic effectors secreted by $C$. falcatum may be recognized by guarded/decoy proteins and ETI gets activated. Whereas, in $\mathrm{Cl}$, the effector may have the ability to inactivate the $\mathrm{R}$ gene products and induce pathogenicity, which can be termed as effector triggered susceptibility (ETS) (Jones and Dangl 2006). The $C$. falcatum pathotype $C f 94012$ has probably induced ETS in host cv Co 7805 by secreting effector 
proteins. Recently, two probable molecular signatures from C. falcatum viz., CfEPL1 (eliciting plant response-like protein 1, a ceratoplatanin protein) and CfPDIP1 (plant defense inducing protein 1, a novel protein) were found and their Functional characterization of the respective genes revealed that they induce HR in tobacco and systemic resistance against $C$. falcatum in sugarcane. These studies have indicated that these PAMPs/Effectors of $C$. falcatum may govern PAMP-triggered immunity (PTI)/effector-triggered immunity (ETI) in sugarcane (Ashwin et al. 2017, 2018). The gene expression of three transcripts differentially regulated from RRL and SRL pertaining to $\mathrm{Ca}^{2+}$ signals, the CDPK, CNGC and calcium binding protein CML (CBP CML) were quantified in qRT-PCR in cv Co 7805 inoculated with two different $C$. falcatum pathotypes. For all the transcripts, the $\mathrm{ICl}$ showed upto 3.8-fold expression whereas in $\mathrm{Cl}$, less than 1.5 -fold expression was noticed (Fig. 4). This proves the probable involvement of all the transcripts of $\mathrm{Ca}^{2+}$ signalling in host resistance to $C$. falcatum.

In this study, several transcripts involved in provoking defense responses like clathrin heavy chain, PCD 6 interacting protein and transcripts involved in PI signalling were found only in ICl. In addition, this study has documented the crucial role of secretory pathway and vesicle trafficking in HR-PCD. The presence of clathrin heavy chain, PCD 6 interacting protein and signal peptidase transcripts in ICl and its absence in $\mathrm{Cl}$ is a convincing factor to determine that PCD takes place at a rapid phase only in ICl. In $\mathrm{Cl}, \mathrm{PCD}$ may not be a response which gives place for successful pathogenicity and disease spread. In this study, only few transcripts pertaining to secretory pathway were commonly expressed in both the interactions $\mathrm{ICl}$ and $\mathrm{Cl}$. But most of the important transcripts namely PCD6 interacting protein and signal peptidase were upregulated only in the ICl. This proves the involvement and possible role of secretory pathway in HRPCD. In a typical R-Avr gene interaction, few rapidly elicited proteins like Avr9/Cf9 are reported and in sugarcane, the transcript was found upregulated in the resistant cultivar (Sathyabhama et al 2015). Avr9/Cf-9-induced F-Box1 (ACIF1; ACRE189) is an F-box protein with a leucine-rich-repeat domain found in a screen to identify proteins involved in Cf9-mediated ETI in N. benthamiana (Rowland et al. 2005). ACIF1 is widely conserved and is closely related to F-box proteins that regulate plant hormone signaling in Arabidopsis. Silencing of ACIF1 Arabidopsis homologs (VFBs) induced a subset of methyl jasmonateand ABA-responsive genes, supporting a regulatory role of ACIF1/VFBs in hormone-mediated plant defense responses (van den Burg et al. 2008). Janjusevic et al. (2006) gave direct evidence on how the bacterial-secreted proteins act as an E3 ligase in plant cells and affect the host defense response. When the Pseudomonas syringae-type III effector AvrPtoB is delivered into tomato plants containing the Pto resistance gene, it elicits PCD that inhibits pathogen invasion. In contrast, AvrPtoB suppresses programmed cell death (PCD) in the Pto-absent plants, leading to rapid pathogen spread in the infected tissues. Structural analysis indicated that the $\mathrm{C}$-terminal region of AvrPtoB is highly homologous to the Ubox and RING-finger domain of eukaryotic E3 ligases. In vitro E3 ligase activity assay indicated that it has ubiquitin ligase activity. Mutation of the conserved residues in the U-box/RING-finger motif of AvrPtoB significantly compromised AvrPtoB's anti-PCD activity in tomato leaves and dramatically reduced disease symptom on infected plants. These results clearly demonstrated that $P$. syringae use an E3 ligase effector protein to suppress plant PCD and probably other defense-related processes in the infected cells. Similarly, in this study, a few Ub-ligases are upregulated only in the ICI and a specific F-box and DNA 
damage binding proteins were found only in the $\mathrm{Cl}$ (Table 3). This could be because of the host modification strategies followed by the pathogen. Still this study provides a new insight on the involvement of UPS in sugarcane and $C$. falcatum interaction. It is novel information in this particular host pathogen interaction. Our recent studies suggest that micro(mi)RNAs regulate many target genes that are involved in inciting early responses to $C$. falcatum infection during the incompatible and compatible interactions in sugarcane against $C$. falcatum. We identified miRNA miR5568b involved in chloroplast and mitochondrial function, HR response, enhancing JA and SA accumulation, a fungal responsive miRNA miR169b.3p regulating phenylpropanoid biosynthesis, post-transcriptional gene regulation, inner membrane transporter by HR response and defense-related miRNA, miR166b.5p involved in increasing resistance by activating ETI, PTI, and ER stress in the host-pathogen interaction (Nandakumar et al. 2021b). The network of miRNAs identified in sugarcane - $C$. falcatum interaction me has validated the present findings in the role of signalling molecules and regulatory genes.

\section{Conclusion}

This study has provided new insights in to the molecular mechanisms of resistant and susceptible responses of sugarcane in response to $C$. falcatum through a detailed transcriptomic approach. This is the first report which indicates the association of signals likes MAPK, $\mathrm{Ca}^{2+}, \mathrm{JA}, \mathrm{PI}, \mathrm{ET}, \mathrm{ROS}, \mathrm{ABA}$ and $\mathrm{BR}$ in an incompatible interaction, whereas in compatible interaction, the absence of MAPK, PI and ET signals indicated that the resistance mechanism is confined to MAPK, PI and ET signals. Also, in $\mathrm{Cl}$ the pathogen has developed its dynamic nature to evade host detection. The upregulation of $\mathrm{AGT}$ in $\mathrm{Cl}$ is a convincing factor to determine the pathogenesis of $C$. falcatum at the transcript level. Also, the involvement of chloroplastic photosystem proteins, the ubiquitin proteasome system and the differential expression of a CNGC protein in providing defense responses to this pathogen in sugarcane system are novel finding in this study. Further, this study has provided evidence on the essential role of pathogenic determinants of C. falcatum establishment inside the host tissue. The probable adaptive mechanisms exhibited by the pathogen and its ability to modify host defense mechanisms are reported for the first time. Further, the hypothesis developed by this study goes in parallel with the zig zag model of plant immunity, where in ICI based on the transcripts upregulated, the immune reaction is PTI-ETS+ETI exists. In Cl, PTI-ETS+ETI exist (Fig. 5). This study has framed a new dimension to look into the enigmatic sugarcane $-C$. falcatum interaction and has proved its occurrence in a logical way.

\section{Declarations}

\section{Acknowledgements}

The author is grateful to the Director of the Institute for the support.

\section{Funding}


The research work was supported by Indian Council of Agricultural Research (ICAR), New Delhi, India through the outreach research programme "ALCOCERA".

\section{Author Contribution Statement}

$\mathrm{RV}$ conceived, designed and received funds for the research work. MS conducted the experiments. PM and ARS analyzed the data. MS and CNP analyzed NGS data. MS and RV wrote the manuscript. All authors read and approved the manuscript.

\section{Compliance with Ethical Standards}

The authors declare that they have no conflict of interest.

The present research did not involve human participants and/or animals

Informed consent was obtained from all individual participants included in the study

\section{References}

1. Ali GS, Reddy ASN (2000) Inhibition of fungal and bacterial plant pathogens by synthetic peptides: in vitro growth inhibition, interaction between peptides and inhibition of disease progression. Mole Plant-Microbe Interact 13:847-859

2. Ashwin NMR, Barnabas EL, Sundar AR, Malathi P, Viswanathan R, Masi A, Agrawal GK, Rakwal R (2017) Comparative secretome analysis of Colletotrichum falcatum identifies a cerato-platanin protein (EPL1) as a potential pathogen-associated molecular pattern (PAMP) inducing systemic resistance in sugarcane. J Proteomics 169:2-20. https://doi.org/10.1016/j.jprot.2017.05.020

3. Ashwin NMR, Barnabas EL, Sundar AR, Malathi P, Viswanathan R, Masi A, Agrawal GK, Rakwal R (2018) CfPDIP1, a novel secreted protein of Colletotrichum falcatum, elicits defense responses in sugarcane and triggers hypersensitive response in tobacco. Appl Microbiol Biotechnol 102:60016021. https://doi.org/10.1007/s00253-018-9009-2

4. Asnaghi C, Roques D, Ruffel S, Kaye C, Hoarau JY, Telismart H, D'Hont A (2004) Targeted mapping of a sugarcane rust resistance gene (Bru1) using bulked segregant analysis and AFLP markers. Theor Appl Gene 108:759-764

5. Beers E, McDowell J (2001) Regulation and execution of programmed cell death in response to pathogens, stress and developmental cues. Curr Opin Plant Biol 4:561-567

6. Bhadauria V, Banniza S, Vandenberg A, Selvaraj G, Wei Y (2012a) Peroxisomal alanine: glyoxylate aminotransferase AGT1 is indispensable for appressorium function of the rice blast pathogen, Magnaporthe oryzae. PLoS ONE 7(4):e36266

7. Bhadauria V, Banniza S, Vandenberg A, Selvaraj G, Wei Y (2012b) Alanine: Glyoxylate aminotransferase 1 is required for mobilization and utilization of triglycerides during infection process of the rice blast pathogen, Magnaporthe oryzae. Plant Signal Behav 7(9):1206-1208 
8. Flor HH (1971) Current status of the gene-for-gene concept. Ann Rev Phytopathol 9:275-296. http://dx.doi.org/10.1146/annurev.py.09.090171.001423

9. Gao X, Neufeld TP, Pan D (2000) Drosophila PTEN regulates cell growth and proliferation through PI3K-dependent and -independent pathways. Dev Biol 221:404-

10. Grant G, More LJ, McKenzie NH, Dorward PM, Buchan WC, Telek L, Pusztai A (1995) Nutritional and haemagglutination properties of several tropical seeds. J Agric Sci 124:437-445

11. Hamdoun S, Liu Z, Gill M, Yao N, Lu H (2013) Dynamics of defense responses and cell fate change during Arabidopsis-Pseudomonas syringae interactions. PLoS ONE 8(12):e83219. https://doi.org/10.1371/journal.pone.0083219

12. Janjusevic R, Abramovitch RB, Martin GB, Stebbins CE (2006) A bacterial inhibitor of host programmed cell death defenses is an E3 ubiquitin ligase. Science 311:222-226

13. Jones JD, Dangl JL (2006) The plant immune system. Nature 444:323-329

14. Kaku H, Nishizawa Y, Ishii-Minami N, Akimoto-Tomiyama C, Dohmae N, Takio K, Shibuya N (2006) Plant cells recognize chitin fragments for defense signaling through a plasma membrane receptor. Proc Natl Acad Sci USA 103:11086-11091

15. Kumar VG, Viswanathan R, Malathi P, Nandakumar M, Sundar AR (2015) Differential Induction of 3deoxyanthocyanidin phytoalexins in relation to Colletotrichum falcatum resistance in sugarcane. Sugar Tech 17:314-321

16. Malathi P, Viswanathan R, Padmanaban P, Mohanraj D, Kumar VG, Salin KP (2008) Differential accumulation of 3-deoxy anthocyanidin phytoalexins in sugarcane varieties varying in red rot resistance in response to Colletotrichum falcatum infection. Sugar Tech 10:154-157

17. Nandakumar M, Malathi P, Sundar AR, Rajadurai CP, Philip M, Viswanathan R (2021b) Role of miRNAs in the host-pathogen interaction between sugarcane and Colletotrichum falcatum, the red rot pathogen. Plant Cell Rept 40:851-870. DOI:10.1007/s00299-021-02682-9

18. Nandakumar M, Malathi P, Sundar AR, Viswanathan R (2021a) Host-pathogen interaction in sugarcane and red rot pathogen: Exploring expression of phytoalexin biosynthesis pathway genes. Indian Phytopathol 74:529-535. DOI: 10.1007/s42360-020-00306-y

19. Prasanth CN, Viswanathan R, Malathi P, Sundar AR, Tiwari T, Krishna N (2017) Unraveling the genetic complexities in gene set of sugarcane red rot pathogen Colletotrichum falcatum through transcriptomic approach. Sugar Tech 19:604-615. DOI: 10.1007/s12355-017-0529-3

20. Pratima PT, Raveendran M, Kumar KK, Rahul PR, Kumar VG, Viswanathan R, Sundar AR, Malathi P, Sudhakar D, Balasubramanian P (2013) Differential regulation of defense-related gene expression in response to red rot pathogen Colletotrichum falcatum infection in sugarcane. Appl Biochem Biotechnol 171:488-503. DOI 10.1007/s12010-013-0346-4

21. Rahul PR, Kumar VG, Sathyabhama M, Viswanathan R, Sundar AR, Malathi P (2015) Characterization and 3D structure prediction of chitinase induced in sugarcane during pathogenesis of Colletotrichum falcatum. J Plant Biochem Biotechnol 24:1-8. DOI: 10.1007/s13562-013-0226-6 
22. Rahul PR, Kumar VG, Viswanathan R, Sundar AR, Malathi P, Prasanth CN, Pratima PT (2016) Defense transcriptome analysis of sugarcane and Colletotrichum falcatum interaction using host suspension cells and pathogen elicitor. Sugar Tech 18:16-28

23. Rowland O, Ludwig AA, Merrick CJ, Baillieul F, Tracy FE, Durrant WE, Jones JD (2005) Functional analysis of Avr9/Cf-9 rapidly elicited genes identifies a protein kinase, ACIK1, that is essential for full Cf-9-dependent disease resistance in tomato. Plant Cell 17:295-310

24. Sathyabhama M, Viswanathan R, Nandakumar M, Malathi P, Sundar AR (2015) Understanding sugarcane defence responses during the initial phase of Colletotrichum falcatum pathogenesis by suppression subtractive hybridization (SSH). Physiol Mol Plant Pathol 91:131-140

25. Sathyabhama M, Viswanathan R, Malathi P, Sundar AR (2016) Identification of differentially expressed genes in sugarcane during pathogenesis of Colletotrichum falcatum by suppression subtractive hybridization (SSH). Sugar Tech 18:176-183

26. Van den Burg HA, Tsitsigiannis DI, Rowland O, Lo J, Rallapalli G, MacLean D, Jones JD (2008) The Fbox protein ACRE189/ACIF1 regulates cell death and defense responses activated during pathogen recognition in tobacco and tomato. Plant Cell 20:697-719

27. Viswanathan R (2010) Plant Disease: Red Rot of Sugarcane, Anmol Publishers, New Delhi, India, p306

28. Viswanathan R (2021a) Red rot of sugarcane (Colletotrichum falcatum Went). CAB Reviews 16(023). doi: 10.1079/PAVSNNR202116023

29. Viswanathan $R$ (2021b) Sustainable sugarcane cultivation in India through threats of red rot by varietal management. Sugar Tech 23:239-253. DOI: 10.1007/s12355-020-00882-3

30. Viswanathan R, Malathi P, Sundar AR, Aarthi S, Premkumari SM, Padmanaban P (2005) Differential induction of chitinases and thaumatin-like proteins in sugarcane in response to infection by Colletotrichum falcatum causing red rot disease. J Plant Dis Protect 112:537-542

31. Viswanathan R, Nandakumar R, Samiyappan R (2003) Role of pathogenesis-related proteins in rhizobacteria-mediated induced systemic resistance against Colletotrichum falcatum in sugarcane. $\mathrm{J}$ Plant Dis Protect 110:524-534

32. Viswanathan R, Padmanaban P, Selvakumar R (2020) Emergence of new pathogenic variants in Colletotrichum falcatum, stalk infecting ascomycete in sugarcane: role of host varieties. Sugar Tech 22:473-484. DOI: 10.1007/s12355-019-00780-3

33. Viswanathan R, Prasanth CN, Malathi P, Sundar AR (2016) Draft genome sequence of Colletotrichum falcatum - a prelude on screening of red rot pathogen in sugarcane. J Genomics 4:1-3. doi: 10.7150/jgen. 13585

34. Viswanathan R, Rao GP (2011) Disease scenario and management of major sugarcane diseases in India. Sugar Tech 13:336-353

\section{Tables}


Table 1. Primer sequences of selected transcripts used in gene expression assays 


\begin{tabular}{|c|c|c|}
\hline Transcript name & \multicolumn{2}{|c|}{ Primer sequences 5'-3' } \\
\hline \multirow[t]{2}{*}{ Chitin elicitor binding protein } & $\mathrm{F}$ & TGCGCGTCCAGGATGTGTG \\
\hline & $\mathrm{R}$ & ATGACGGACGTCCTCCACATGG \\
\hline \multirow[t]{2}{*}{ Mitogen activated protein kinase kinase kinase 1} & $\mathrm{~F}$ & GGTGCTGCTGATATACAGACAGGC \\
\hline & $\mathrm{R}$ & GGACCAGACTTGGGGCGTG \\
\hline \multirow[t]{2}{*}{ Mitogen activated protein kinase kinase 1} & $\mathrm{~F}$ & GGTGCTGCTGATATACAGACAGG \\
\hline & $\mathrm{R}$ & ACCAGACTTGGGGCGTGTAAT \\
\hline \multirow[t]{2}{*}{ Brassinosteroid signaling kinase } & $\mathrm{F}$ & CAGCACACGGCCCGTTA \\
\hline & $\mathrm{R}$ & CTGTGACGCATTTTTTGGGCC \\
\hline \multirow[t]{2}{*}{ Disease resistance protein RPM1 } & $\mathrm{F}$ & GTGCAGGGTGGTTCCCTAAGCT \\
\hline & $\mathrm{R}$ & GGTGGAGTGTCCTAAGGTACTGGATG \\
\hline \multirow[t]{2}{*}{ Disease resistance protein RPS5 } & $\mathrm{F}$ & GGCAGGGTTGGAAGGACCAAG \\
\hline & $\mathrm{R}$ & CCATATTCTGGGAAAAGGGTGCAG \\
\hline \multirow[t]{2}{*}{ Cyclic nucleotide gated channel } & $\mathrm{F}$ & CGCGATTGCCAACGACAG \\
\hline & $\mathrm{R}$ & TGCAGCAGTCTTGCAGGCA \\
\hline \multirow[t]{2}{*}{ Calcium dependent protein kinase } & $\mathrm{F}$ & GCACACCGGCTTGACAGACC \\
\hline & $\mathrm{R}$ & GTGGCTGTGCCAAGTTCATTTGCC \\
\hline \multirow[t]{2}{*}{ Calcium binding protein $\mathrm{CML}$} & $\mathrm{F}$ & ACACCAGTCAATAAGCACACGCC \\
\hline & $\mathrm{R}$ & AGGATTGCCAAAGAGCTGGGTG \\
\hline \multirow[t]{2}{*}{ Superoxide dismutase Cu-Zn family } & $\mathrm{F}$ & GCTGAGGGCGTAGCTGAGG \\
\hline & $\mathrm{R}$ & GCCAACAACACCACATGCCAGT \\
\hline \multirow[t]{2}{*}{ V type proton transporting ATPase subunit1 } & $\mathrm{F}$ & GAGCTTGGCGCATTCAGAGCTG \\
\hline & $\mathrm{R}$ & GCAGTGCATGCAGGAAGGCA \\
\hline \multirow[t]{2}{*}{ Jasmonic acid amino acid synthetase } & $\mathrm{F}$ & AGCCATTGGCCCACTTGAG \\
\hline & $\mathrm{R}$ & GGTGGTGTTCCTACTTAGTATCTGC \\
\hline \multirow[t]{2}{*}{ Abscisic acid responsive element binding factor } & $\mathrm{F}$ & GGCACTGGTACACTCGACTCTG \\
\hline & $\mathrm{R}$ & CGATGCCTGCGGAGAACATTGA \\
\hline \multirow[t]{2}{*}{ Ethylene receptor } & $\mathrm{F}$ & TCGGTTTCCTCCGCTTTGAG \\
\hline & $\mathrm{R}$ & TGTGAAGGCTGACTCTTTGAGAGA \\
\hline
\end{tabular}




\begin{tabular}{|lll|} 
14-3-3 protein epsilon & F & CGCATGCTCCCTCGCCA \\
\cline { 2 - 3 } Chitinase & R & CGTCAGGCTTGCTTGCATCCC \\
& F & GCTGCAGATCTCGTGGAACTACAAC \\
\hline 25SrRNA & R & GTGCACGTTGTTCGTCCAGAAC \\
& F & GGCAGCCAAGCGTTCATAGC \\
\hline R & GGGTAAAACTAACCTGTCTCACGAC \\
\hline
\end{tabular}

Table 2: Representative GO of RR and SR through BLAST homology search 


\begin{tabular}{|c|c|c|c|}
\hline & RRL & & SRL \\
\hline \multicolumn{4}{|c|}{ GObiological process } \\
\hline 1.transcript 266 & aromatic amino acid family biosyntheticprocess; & transcript_ 177 & sucrose biosynthetic process; \\
\hline 2 transcript 681 & protein N-linked glycosylation; & transcript_254 & negative regulation of peptidase activity; \\
\hline 3 transcript 789 & small GTPase mediated signal transduction; & transcript_373 & spermine biosynthetic process; spermidine biosynthetic process; \\
\hline 4 transcript 2602 & D-amino acid catabolicprocess; & transcript_499 & protein deubiquitination; post-translational protein modification; \\
\hline 5 transcript_2826 & one-carbon metabolic process; & & \\
\hline 6 transcript_2942 & GPl anchor biosyntheticprocess; & & \\
\hline 7 transcript 3315 & \multicolumn{3}{|c|}{ two-component signal transduction system (phosphorelay); peptidy/-histidine phosphorylation; } \\
\hline 8 transcript 4821 & IMP biosynthetic process; & & \\
\hline 9 transcript 4947 & small GTPase mediated signal transduction; & & \\
\hline 10: transcript 5013 & meiotic chromosome segregation; & & \\
\hline 11 transcript 5441 & oxidation-reduction process; terpenoid biosynthetic process; & & \\
\hline 12 :transcript 6927 & Inositol trisphosphate metabolic process; & & \\
\hline \multicolumn{4}{|c|}{ GO celluar com ponent } \\
\hline 13 transcript 1452 & RNA polymerase complex; & transcript_2078 & cullin-RING ubiquitin ligase complex; \\
\hline 14 transcript 2324 & cis-Golgi network; & & \\
\hline 15 :transcript 3744 & low-density lipoprotein particle; high-density lipoprotein particle; & & \\
\hline 16: transcript 4014 & anaphase-promoting complex; & & \\
\hline 17 transcript_ 4349 & cell junction; cell wall; & & \\
\hline 18 transcript 7732 & transcription factor TFIIID complex; & & \\
\hline 19: transcript 7780 & photosystem l; chloroplastthylakoid membrane; & & \\
\hline 20: :ranscript 7849 & photosystem II; integral to membrane; chloroplast thylakoid memb & & \\
\hline \multicolumn{4}{|c|}{ GOm decular function } \\
\hline 21 transcript 266 & shikimate kinase activity; ATP binding; magnesium ion binding; & transcript 254 & serine-type endopeptidase inhibitor activity; peptidase activity; \\
\hline 22 transcript 855 & \multicolumn{2}{|c|}{ P-P-bond-hydrolysis-driven protein transmembrane transporteracti transcript_2789 } & quinone binding; oxidoreductase activity, acting on NADHor NADP \\
\hline 23 transcript 1184 & \multicolumn{2}{|c|}{ mannosyl-oligosaccharide 1,2-alpha-mannosidase activity; calcium ion binding; } & \\
\hline 24 transcript 1517 & cellulose synthase (UDP-forming) activity; & & \\
\hline 25 :transcript_ 1884 & SNAP receptor activity; & & \\
\hline 26 :transcript 3369 & \multicolumn{2}{|l|}{ P-P-bond-hydrolysis-driven protein transmembrane transporteractivity; } & \\
\hline 28 : transcript 4062 & N-acetyltransferase activity; & & \\
\hline 29:transcript_ 4097 & aspartic-type endopeptidase activity; & & \\
\hline 30: transcript 6112 & serine-type endopeptidase activity; & & \\
\hline 31: transcript_ 6411 & mannose-1-phosphate guanylyltransferase (GDP) activity; & & \\
\hline 32 : transcript 6927 & \multicolumn{3}{|c|}{ Inositol-1,3,4-trisphosphate 5/6-kinase activity; inositol tetrakisphosphate 1-kinase activity; ATP binding; magnesium ion binding; } \\
\hline 33 :transcript_ 1987 & NADH dehydrogenase (ubiquinone) activity; & & \\
\hline
\end{tabular}

Table 3. Representative differential transcripts from RRL and SRL and their putative function as mapped in KEGG-KASS database 


\begin{tabular}{|c|c|c|c|c|}
\hline S.No & Transcripts & Function & RR & SR \\
\hline 1 & Chitin elicitor binding protein (CEBiP) & Recognition & $\sqrt{ }$ & $\sqrt{ }$ \\
\hline 2 & Serine Threonine protein kinase (STPK) & Signalling & $\sqrt{ }$ & $\sqrt{ }$ \\
\hline 3 & $\begin{array}{l}\text { Mitogen activated protein kinase kinase kinase } 1 \\
\text { (MAPKKK1) }\end{array}$ & Signalling & $\sqrt{ }$ & $\mathrm{x}$ \\
\hline 4 & $\begin{array}{l}\text { Mitogen activated protein kinase kinase } 1 \\
\text { (MAPKK1) }\end{array}$ & Signalling & $\sqrt{ }$ & $x$ \\
\hline 5 & Disease resistance protein RPM1 (DRP RPM1) & Defense & $\sqrt{ }$ & $\mathrm{x}$ \\
\hline 6 & Disease resistance protein RPS2 (DRP RPS2) & Defense & $\sqrt{ }$ & $\mathrm{x}$ \\
\hline 7 & Disease resistance protein RPS5 (DRP RPS5) & Defense & $\sqrt{ }$ & $\mathrm{x}$ \\
\hline 8 & Protein kinase (PK) & Signalling & $\sqrt{ }$ & $\mathrm{x}$ \\
\hline 9 & Brassinosteroid signalling kinase (BRSK) & Signalling & $\sqrt{ }$ & $\sqrt{ }$ \\
\hline 10 & 14-3-3 protein (14-3-3 $P)$ & Multifaceted roles & $\sqrt{ }$ & $\sqrt{ }$ \\
\hline 11 & Phospholipase C (PLC) & Signalling & $\sqrt{ }$ & $\sqrt{ }$ \\
\hline 12 & Phospholipase D (PLD) & Signalling & $\sqrt{ }$ & $\sqrt{ }$ \\
\hline 13 & Phosphoinositide 3 kinase (PI3K) & Signalling & $\sqrt{ }$ & $\mathrm{x}$ \\
\hline 14 & Phosphoinositide 4 kinase (PI4K) & Signalling & $\sqrt{ }$ & $\mathrm{x}$ \\
\hline 15 & Linoleate 9S lipoxygenase (LOX) & Signalling & $\sqrt{ }$ & $\mathrm{x}$ \\
\hline 16 & Jasmonic acid amino synthetase (JAAS) & Signalling & $\sqrt{ }$ & $x$ \\
\hline 17 & Calcium binding protein $\mathrm{CML}(\mathrm{CBP} \mathrm{CML})$ & Signalling & $\sqrt{ }$ & $\sqrt{ }$ \\
\hline 18 & Calcium binding protein 39 (CBP 39) & Signalling & $\sqrt{ }$ & $\mathrm{x}$ \\
\hline 19 & Calmodulin (CaM) & Signalling & $\sqrt{ }$ & $\sqrt{ }$ \\
\hline 20 & Calcium dependent protein kinase (CDPK) & Signalling & $\sqrt{ }$ & $\sqrt{ }$ \\
\hline 21 & Cyclic nucleotide gated channel (CNGC) & Redox homeostasis & $\sqrt{ }$ & $x$ \\
\hline 22 & Respiratory burst oxidase (RBO) & Oxidative stress & $\sqrt{ }$ & $\sqrt{ }$ \\
\hline 23 & Catalase (CAT) & Oxidative stress & $\sqrt{ }$ & $\sqrt{ }$ \\
\hline 24 & Superoxide dismutase (SOD) & Oxidative stress & $\sqrt{ }$ & $\sqrt{ }$ \\
\hline 25 & Glutathione peroxidase (GPOX) & Oxidative stress & $\sqrt{ }$ & $\sqrt{ }$ \\
\hline 26 & L-Ascorbate peroxidase (L-APX) & Oxidative stress & $\sqrt{ }$ & $\sqrt{ }$ \\
\hline 27 & Peroxidase (POX) & Oxidative stress & $\sqrt{ }$ & $\sqrt{ }$ \\
\hline
\end{tabular}




\begin{tabular}{|c|c|c|c|c|}
\hline 28 & Glutathione S transferase (GST) & Redox homeostasis & $\sqrt{ }$ & $\sqrt{ }$ \\
\hline 29 & Glutathione $S$ reductase (GSR) & Redox homeostasis & $\sqrt{ }$ & $\sqrt{ }$ \\
\hline 30 & Abscisic acid receptor PYR/PYL (ABAR PYR/PYL) & Signalling & $\sqrt{ }$ & $\sqrt{ }$ \\
\hline 31 & Protein phosphatise $2 \mathrm{C}$ (PP2C) & Signalling & $\sqrt{ }$ & $\sqrt{ }$ \\
\hline 32 & Ethylene receptor (ETR) & Recognition \& Signalling & $\sqrt{ }$ & $x$ \\
\hline 33 & Ethylene insensitive 2 (EIN2) & Signalling & $\sqrt{ }$ & $x$ \\
\hline 34 & Ethylene insensitive 3 (EIN3) & Signalling & $\sqrt{ }$ & $x$ \\
\hline 35 & S-adenosyl methionine synthetase (SAMS) & Secondary metabolism & $\sqrt{ }$ & $\sqrt{ }$ \\
\hline 36 & S-adenosyl methionine decarboxylase (SAMDC) & Secondary metabolism & $\sqrt{ }$ & $\sqrt{ }$ \\
\hline 37 & Hexokinase $(\mathrm{HK})$ & Glycolysis & $\sqrt{ }$ & $x$ \\
\hline 38 & Phosphoglycerate mutase (PGM) & Glycolysis & $\sqrt{ }$ & $x$ \\
\hline 39 & Pyruvate dehydrogenase (PDH) & Glycolysis & $\sqrt{ }$ & $x$ \\
\hline 40 & Succinate dehydratase (SDH) & Tricarboxylic acid cycle & $\sqrt{ }$ & $x$ \\
\hline 41 & Phenylalanine ammonia lyase (PAL) & $\begin{array}{l}\text { Phenyl propanoid } \\
\text { biosynthesis }\end{array}$ & $\sqrt{ }$ & $x$ \\
\hline 42 & 4-Coumarate CoA ligase (4-CouCoAL) & $\begin{array}{l}\text { Phenyl propanoid } \\
\text { biosynthesis }\end{array}$ & $\sqrt{ }$ & $x$ \\
\hline 43 & Coniferyl aldehyde dehydrogenase (ConADH) & $\begin{array}{l}\text { Phenyl propanoid } \\
\text { biosynthesis }\end{array}$ & $\sqrt{ }$ & $x$ \\
\hline 44 & Cinnamyl alcohol dehydrogenase (CinAlcDH) & $\begin{array}{l}\text { Phenyl propanoid } \\
\text { biosynthesis }\end{array}$ & $\sqrt{ }$ & $x$ \\
\hline 45 & Trans-cinnamate 4 monooxygenase (TC4MO) & $\begin{array}{l}\text { Phenyl propanoid } \\
\text { biosynthesis }\end{array}$ & $x$ & $\sqrt{ }$ \\
\hline 46 & Tyrosine aminotransferase (TyrAT) & Alkaloid biosynthesis & $\sqrt{ }$ & $\sqrt{ }$ \\
\hline 47 & Tyrosine decarboxylase (TyrDC) & Alkaloid biosynthesis & $\sqrt{ }$ & $\sqrt{ }$ \\
\hline 48 & Phosphomevalonate kinase (PMK) & Terpenoid biosynthesis & $\sqrt{ }$ & $x$ \\
\hline 49 & Diphosphomevalonate decarboxylase (DPMDC) & Terpenoid biosynthesis & $\sqrt{ }$ & $x$ \\
\hline 50 & Farnesyl diphosphate synthase (FDPS) & Terpenoid biosynthesis & $\sqrt{ }$ & $x$ \\
\hline 51 & Phytoene synthase (PhyS) & Carotenoid biosynthesis & $\sqrt{ }$ & $\mathrm{x}$ \\
\hline 52 & Zeaxanthin epoxidase (ZXEOX) & Carotenoid biosynthesis & $\sqrt{ }$ & $x$ \\
\hline 53 & Violaxanthin de-epoxidase (VXDOX) & Carotenoid biosynthesis & $\sqrt{ }$ & $\mathrm{x}$ \\
\hline 54 & Chalcone synthase (CS) & Flavonoid biosynthesis & $\mathrm{x}$ & $\sqrt{ }$ \\
\hline
\end{tabular}




\begin{tabular}{|lllll|}
\hline 55 & Photosystem I P 700 & Light harvesting complex & $\sqrt{ }$ & $\sqrt{ }$ \\
\hline 56 & Photosystem II & Light harvesting complex & $\sqrt{ }$ & x \\
\hline 57 & Cytochrome b6 & Light harvesting complex & $\sqrt{ }$ & x \\
\hline 58 & Apocytochrome f & Light harvesting complex & x & $\sqrt{ }$ \\
\hline 59 & F-type H+-transporting ATPase subunit & lon transport & $\sqrt{ }$ & $\sqrt{ }$ \\
\hline 60 & Clathrin heavy chain & Secretory pathway & $\sqrt{ }$ & x \\
\hline 61 & Charged multivesicular body protein & Secretory pathway & $\sqrt{ }$ & $\sqrt{ }$ \\
\hline 62 & Vacuolar protein sorting associated protein & Secretory pathway & $\sqrt{ }$ & $\sqrt{ }$ \\
\hline 63 & Ras-related protein & Secretory pathway & $\sqrt{ }$ & $\mathrm{x}$ \\
\hline 64 & $\begin{array}{l}\text { Programmed cell death 6 interacting protein } \\
\text { (PCD6IP) }\end{array}$ & Secretory pathway & $\sqrt{ }$ & $\mathrm{x}$ \\
\hline 65 & E3 ubiquitin protein ligase (E3UbL) & Secretory pathway & $\sqrt{ }$ & $\mathrm{x}$ \\
\hline 66 & Vesicle transport protein & Secretory pathway & $\sqrt{ }$ & $\mathrm{x}$ \\
\hline 67 & Signal recognition particle receptor subunit & Protein processing in ER & $\sqrt{ }$ & $\sqrt{ }$ \\
\hline 68 & Signal peptidase & Protein processing in ER & $\sqrt{ }$ & $\sqrt{ }$ \\
\hline 69 & Chitinase & Defense & $\sqrt{ }$ & $\sqrt{ }$ \\
\hline 70 & Endoglucanase & Defense & $\sqrt{ }$ & $\mathrm{x}$ \\
\hline 71 & Pathogenesis related 1 (PR-1) & Defense & $\sqrt{ }$ & $\mathrm{x}$ \\
\hline 72 & Pectin esterase & Cell wall metabolism & $\mathrm{x}$ & $\sqrt{ }$ \\
\hline
\end{tabular}

RR- Resistance response, SR - Susceptible response, $\sqrt{ }$ - Presence of the transcripts, $x$ - absence of the transcripts

Table 4. Transcript homologous to Glomerella graminicola from SRL identified through BLASTX homology search 


\begin{tabular}{|lll|}
\hline S.No & Transcripts & Function \\
\hline 1 & Endoribonuclease L-PSP & Translation \\
\hline 2 & Hexokinase & Glycolysis \\
\hline 3 & Ribosomal L2 domain containing protein & Translation \\
\hline 4 & G-patch domain containing protein & RNA splicing \\
\hline 6 & 25 s ribosomal protein & Translation \\
\hline 7 & Ribosomal protein s28e & Translation \\
\hline 8 & Hibonucleotide reductase & Translation \\
\hline 9 & Ribosomal protein L18ae protein family & Translation \\
\hline 10 & Ras family protein & Intracellular signal transduction \\
\hline 11 & AMP binding enzyme & Intracellular signal transduction \\
\hline 12 & Sulfate permease & Transmembrane protein \\
\hline 13 & Zinc finger containing protein & Proteasome system \\
\hline 14 & Translation elongation factor EF-1 & Translation \\
\hline 15 & Ribosomal L29e family protein & Translation \\
\hline 16 & Ribosomal protein s12 & Translation \\
\hline 17 & Alanine-glyoxylate amino transferase & Fungal morphogenesis \\
\hline
\end{tabular}

\section{Figures}


1

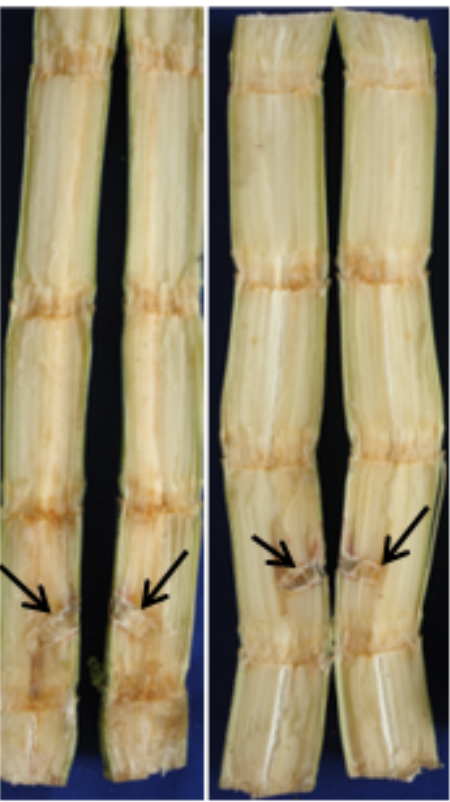

$72 \mathrm{hr}$
1

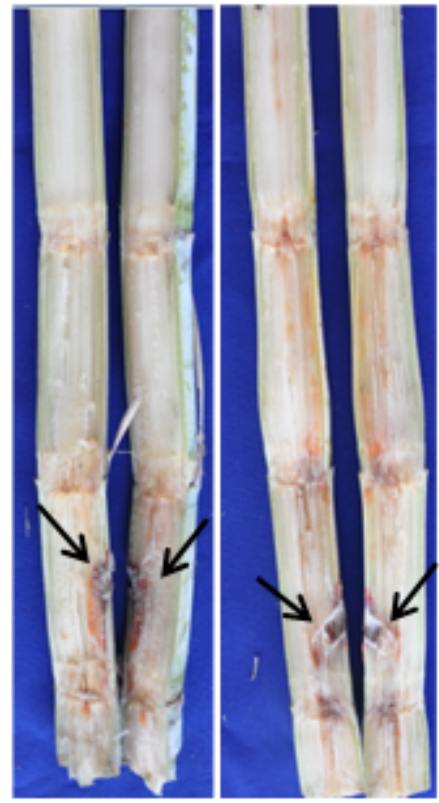

$120 \mathrm{hr}$
2

1

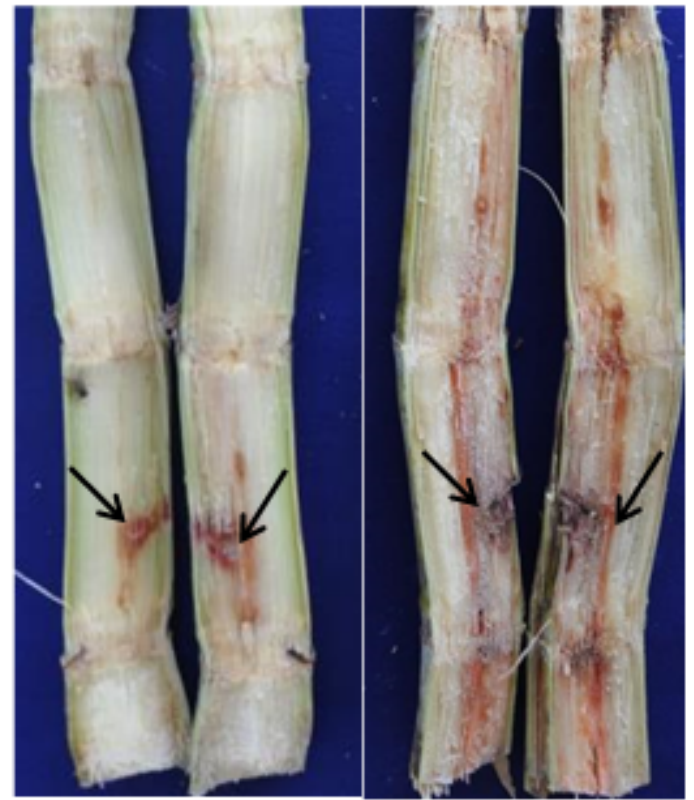

$240 \mathrm{hr}$

Figure 1

Phenotypic symptoms of sugarcane cv Co 7805 exhibiting differential response to inoculation with two different C. falcatum pathotypes Cf87012 (1) and Cf94012 (2); arrows indicate point of pathogen inoculation.

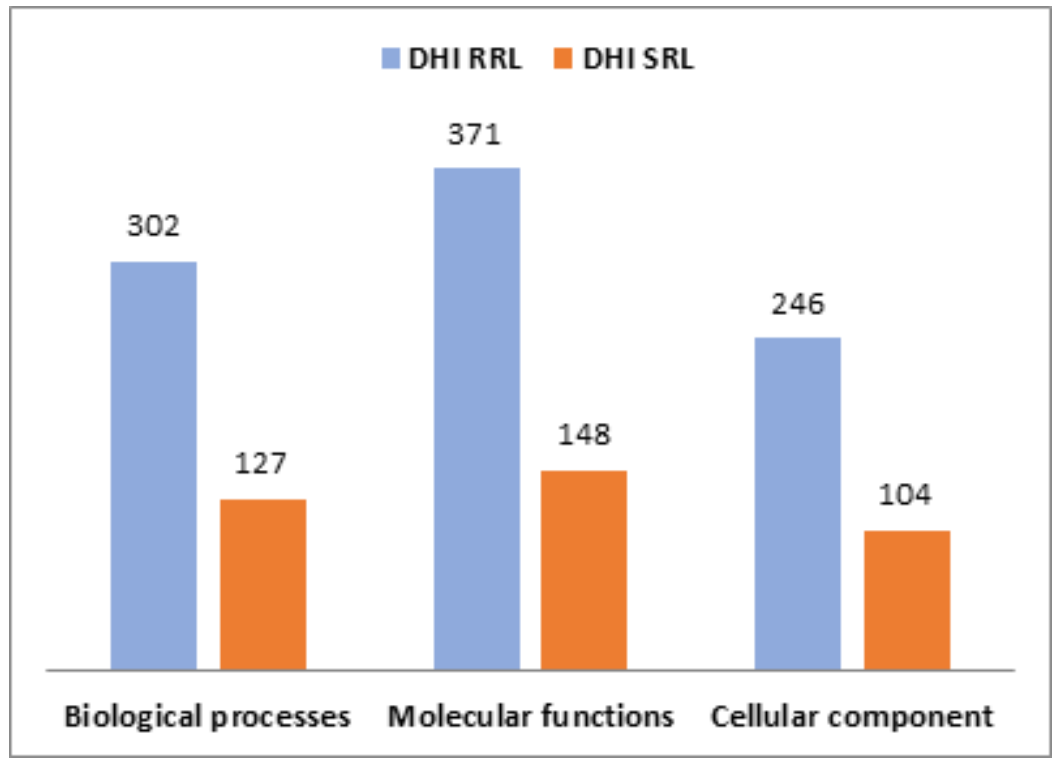

Figure 2

Gene ontology distribution in resistant (RRL) and susceptible (SRL) responses in SSH libraries of sugarcane challenged with virulent and less virulent pathotypes of C. falcatum. 


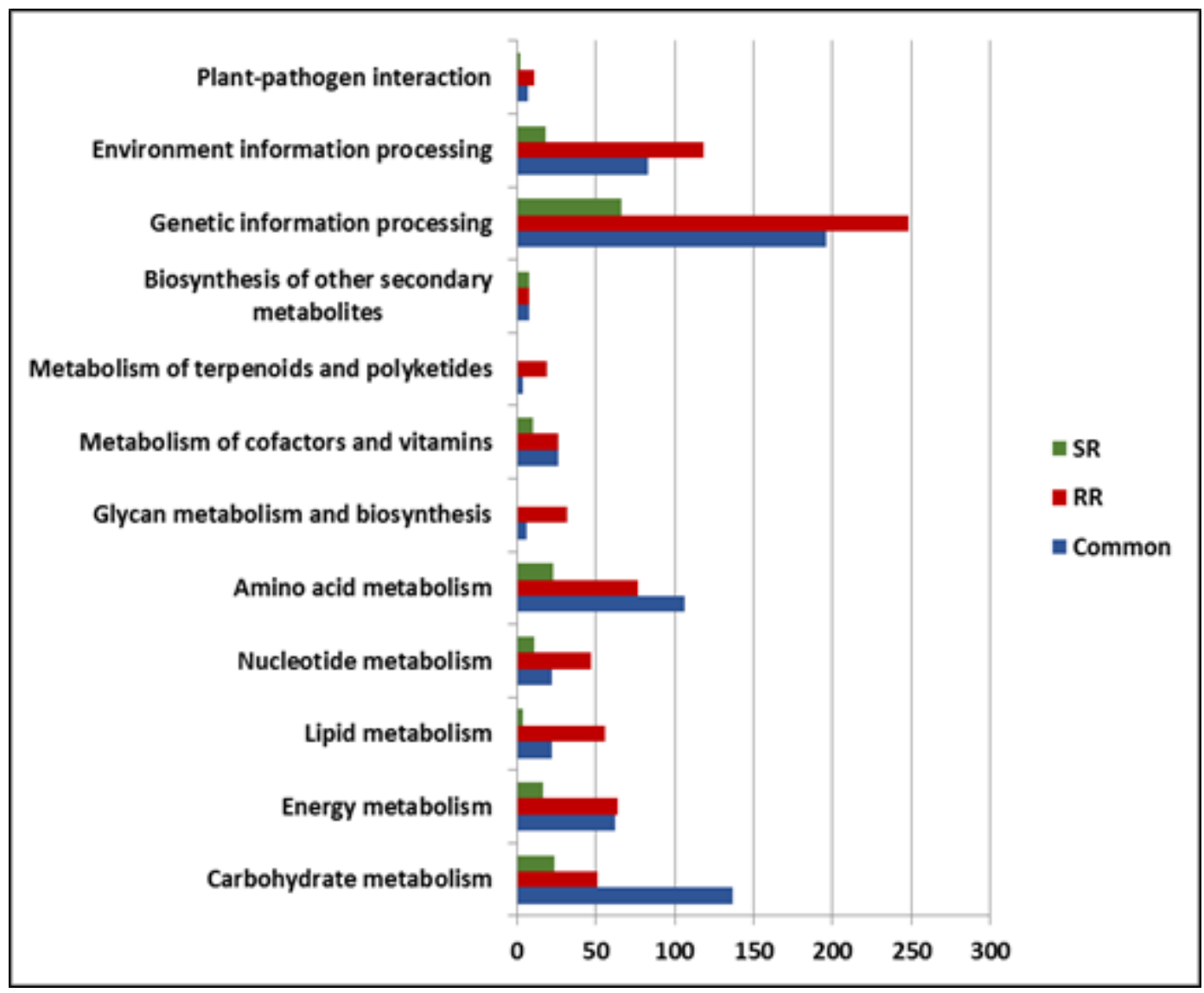

\section{Figure 3}

Functional categorization of transcripts involved in resistant (RR) and susceptible (SR) responses in SSH libraries of sugarcane challenged with virulent and less virulent pathotypes of $\mathrm{C}$. falcatum. 


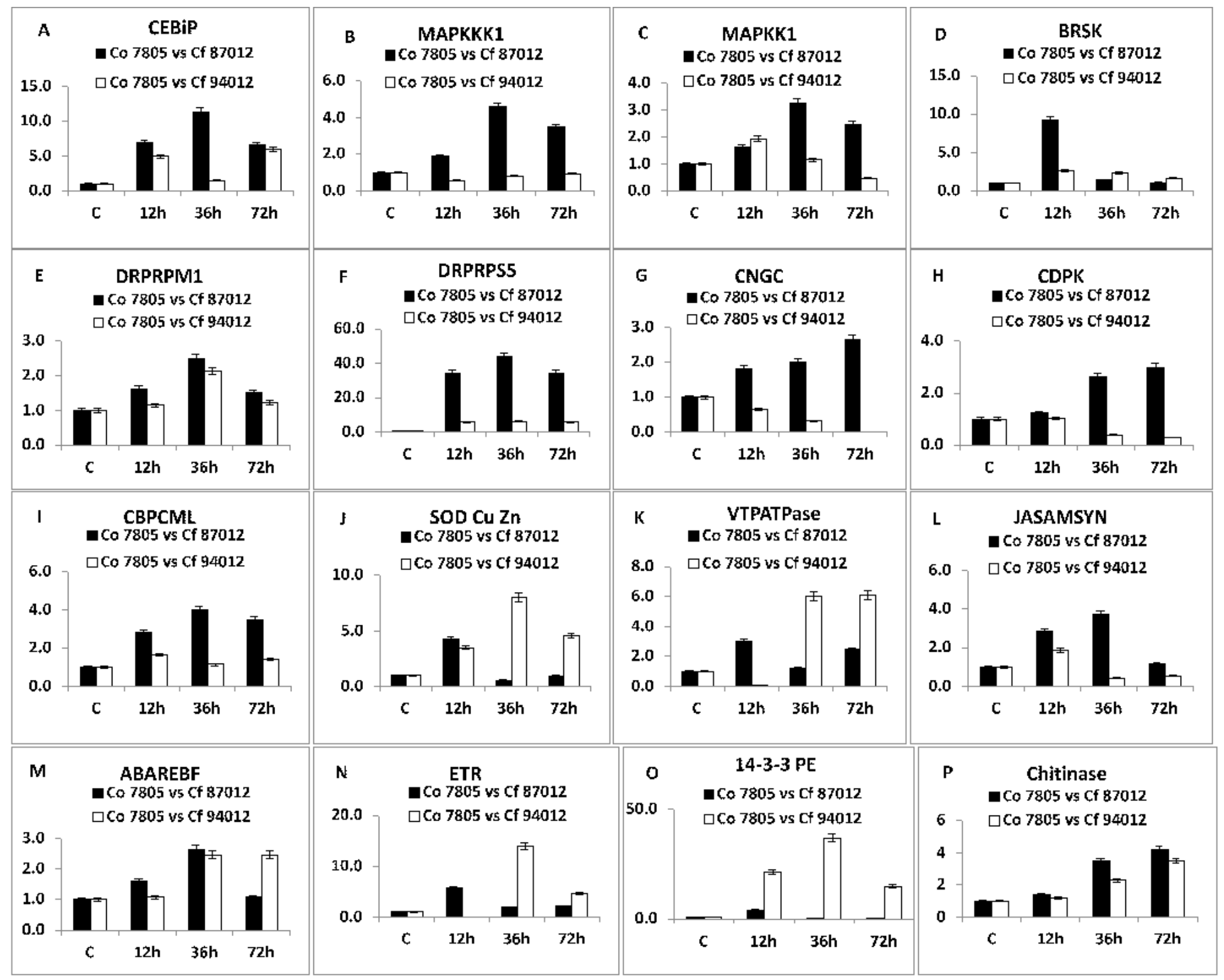

Figure 4

Gene expression profiling of transcripts in incompatible (Co 7805 vs Cf 87012) and compatible interactions (Co 7805 vs Cf 94012). C - Mock control, $h$ - hours post C. falcatum inoculation, $X$ - axis hours post $C$. falcatum inoculation; $Y$ - axis - RQ values 


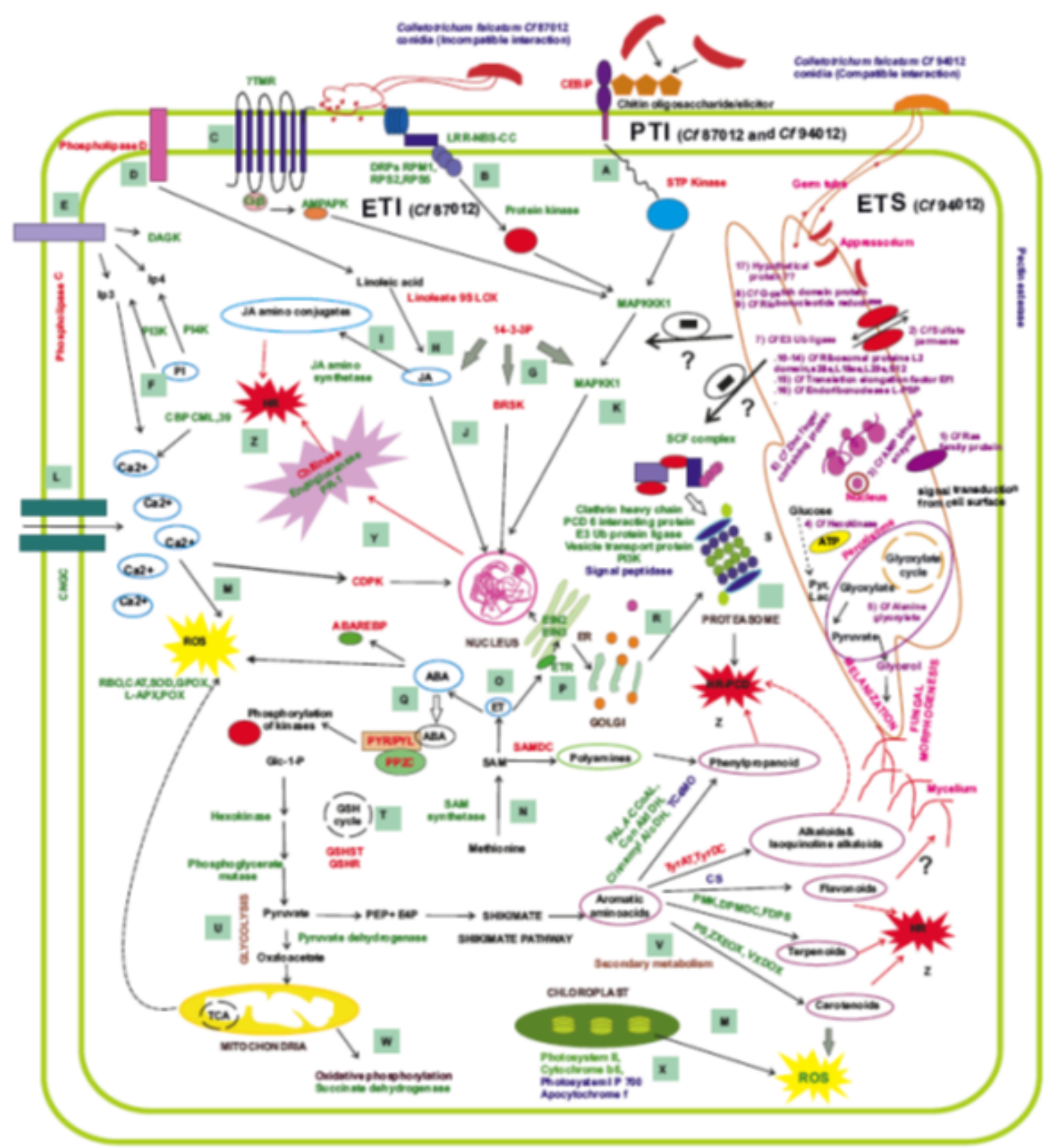

\section{Figure 5}

Schematic representation of probable hypothetical events occurring in sugarcane variety Co 7805 to two different C. falcatum pathotypes during incompatible (Cf87012) and compatible (Cf94012) interactions. Transcripts in green represents those involved in incompatible interaction. Red- transcripts involved in both compatible and incompatible interactions. Blue- transcripts involved compatible interaction. Lavender-represents transcripts involved in the reproductive stage of C. falcatum pathotype Cf 94012 inside the host cells. CEBiP - Chitin elicitor binding protein, LRR-NBS-CC- Leucine rich repeat- Nucleotide binding site, Coiled coil, DRP-Disease resistant protein, RPM1-, RPS2-, RPS5-, STPK- Serine threonine protein kinase, MAPKKK1 - Mitogen activated protein kinase kinase kinase 1, MAPKK1 - Mitogen activated protein kinase kinase 1, BRSK - Brassinosteroid signalling kinase, 14-3-3P - 14-3-3 Protein, JA- 
Jasmonic acid, LOX - Lipoxygenase, DAG - Diacylglyceol, PI, PI3K, PI4K, IP3, IP4,CBP- Calcium binding protein, $\mathrm{Ca} 2+-$ Calcium, CDPK - Calcium dependent protein kinase, CNGC - Cyclic nucleotide gated channel, ROS- Reactive oxygen species, RBO - Respiratory burst oxidase, CAT - Catalase, SOD Superoxide dismutase, GPOX- Glutathione peroxidase, L-APX - L-Ascorbate peroxidase, POX Peroxidase, ABA - Absicisic acid, ABAREBP - ABA response element binding protein, PYR/PYL - ABA receptor, PP2C - SAM - S-adenosyl methionine, SAMDC - SAM decarboxylase, ET- Ethylene, ETR - ET receptor, EIN2 - Ethylene insensitive 2, EIN3 - Ethylene insensitive 3, Glc-1-P - Glucose 1 phosphate, PDH - Pyruvate dehydrogenase, TCA - Tricarboxylic acid cycle, SDH - Succinate dehydrogenase, PEP phosphoenol pyruvate, E4P - Erythrose 4 phosphate, PAL - Phenylalanine ammonia lyase, 4-CCoAL-, CoADH - Coniferyl aldehyde dehydrogenase, $\mathrm{CiADH}$ - Cinnamyl alcohol dehydrogenase, TyrAT-, TyrDC-, PMK-, DPMDC-, FDPS-, PS-, ZXEOX-, VXDOX-, PCD - Programmed cell death-, Ub- Ubiquitin, SCF - Skp1Cullin- F-box, HR - Hypersensitive response, TC4MO-, CS - Chalcone synthase,

\section{Supplementary Files}

This is a list of supplementary files associated with this preprint. Click to download.

- SupplFig1.docx 